American Journal of Infectious Diseases 6 (2): 44-49, 2010

ISSN 1553-6203

(C) 2010 Science Publications

\title{
A Case of Refractory Salmonella Spondylodiscitis in an Immunocompetent Patient Treated Via an Extracavitary Approach, Corpectomy and Placement of Expandable Cage
}

\author{
${ }^{1,2}$ Kimon Bekelis, ${ }^{1}$ Oren Gottfried, ${ }^{1}$ Zyia L. Gokaslan, \\ ${ }^{1}$ Panagiotis Markopoulos and ${ }^{1}$ Ibrahim Omeis \\ ${ }^{1}$ Department of Neurosurgery, Johns Hopkins University School of Medicine, \\ Baltimore, MD \\ ${ }^{2}$ Department of Neurosurgery, Dartmouth-Hitchcock Medical Center, Lebanon, NH 03756
}

\begin{abstract}
Problem statement: Salmonella spondylodiscitis is a rare condition that is more prevalent in patients with sickle cell disease or immunosuppression. However, it can also be found in immunocompetent patients. It usually responds well to proper antibiotics. However, surgery is rarely indicated when the infection is refractory to antibiotics, the spine is destabilized or there is an epidural component that is compressing the thecal sac and causing neurological deficit. We report the case of a 60 year-old African American woman with borderline diabetes mellitus controlled with diet, who presented with Salmonella osteomyelitis of the thoracic spine that was associated with an epidural abscess. Approach: The patient presented to an outside hospital with diarrhea, fever and chills. This occurred after eating a chicken sandwich. Stool and blood cultures were positive for Salmonella. Initially she was placed on triple antibiotics (ceftriaxone, vancomycin and levofloxacin) and was later switched to levofloxacin alone given that the bacteria were sensitive to this drug. Several weeks later, she presented with severe back pain. Imaging studies showed a significant lytic lesion in her thoracic spine at T11-12 with an epidural component. Given the instability of the lesion and the failure of medical treatment a decision was made for surgical intervention. Results: She underwent an extracavitary approach for partial T11-T12 corpectomies and fusion with instrumentation with continuous administration of the proper antibiotics. The patient was then discharged to an acute patient rehabilitation center. Postoperatively, she was able to ambulate with full strength in her extremitiesand her back pain had resolved. Conclusion/Recommendations: To the best of the authors' knowledge this is the first reported case of Salmonella spondylodiscitis in an immunocompetent patient treated with a corpectomy via an extracavitary approach with the use of an expandable cage and posterior instrumentation.
\end{abstract}

Key words: Salmonella, spondylodiscitis, epidural abscess, corpectomy, extracavitary approach, expandable cage

\section{INTRODUCTION}

Despite the fact that salmonella spondylodiscitis accounts for less than $0.5 \%$ of all bone infections, it causes significant difficulties in management and can be associated with increased morbidity and mortality for it usually eludes timely diagnosis (Ozturk et al., 2006; Korovessis et al., 2008). Although it is usually managed with intravenous antibiotics, surgical intervention is indicated in cases of neurological compromise, spinal deformity and concomitant epidural abscess (Arnold et al., 1997). The usual need for a corpectomy during the operation makes the stable reconstruction of the anterior column of the spine imperative. The use of titanium mesh cages and most recently expandable cages through an anterior approach has revolutionaries this process (Korovessis et al., 2008; Hee et al., 2002; Kuklo et al., 2006; Liljenqvist et al., 2003; Fang et al., 1994; Altman et al., 1996; Bhat et al., 1999; Auguste et al., 2006; Arts and Peul, 2008). In an effort to minimize the morbidity associated with the anterior approach, we report to the best of our knowledge the first case of vertebral osteomyelitis to be treated with an extracavitary approach. In fact this appears to be the first case of salmonella spondylodiscitis in an immunocompetent patient in which an expandable cage was used.

Corresponding Author: Kimon Bekelis, Department of Neurosurgery, Dartmouth-Hitchcock Medical Center, Lebanon, NH 03756 Tel: 603-650-5130 Fax: 603-650-4547 


\section{MATERIALS AND METHODS}

Presentation: This 60 year-old African-American woman with a history of childhood rickets, borderline Diabetes Mellitus (DM) type 2and arterial hypertension developed food poisoning characterized by severe diarrhea after eating a chicken sandwich. She was admitted to an outside hospital with dehydration, fever and chills. Stool and blood cultures were positive for salmonella. She was initially started on triple antibiotics (vancomycin, ceftriaxoneand levofloxacin). She was then kept on levofloxacin alone since the bacteria were sensitive to this antibiotic. The patient did well and was discharged home on levofloxacin to return to the outside hospital several weeks later with fever, chills, severe back pain and inability to walk. On further questioning, she revealed that she had recently fallen from a standing position. Her physical exam revealed that she was febrile $\left(\mathrm{T} 102^{\circ} \mathrm{F}\right)$. Her strength in her lower extremities was full. However, she was unable to ambulate due to pain. Her sensory examination was intact to light touch and pinprick. Her spine was tender to palpation at the thoracolumbar junction. Computed Tomography (CT) and Magnetic Resonance (MR) imaging of the thoracolumbar spine revealed a destructive lesion at T11 and T12 causing a kyphotic deformity with a retropulsed fragment into the spinal canal Fig. 1 and an epidural abscess causing spinal cord compression Fig. 2 and 3 Imaging studies of the rest of her spine did not reveal any other sites of infection. Laboratory findings included a White Blood Cell (WBC) count of $13,200 \mathrm{~mm}^{-3}$, C-Reactive Protein (CRP) of $22.3 \mathrm{mg} \mathrm{dL}^{-1}$ and Erythrocyte Sedimentation Rate (ESR) of $82 \mathrm{~mm} \mathrm{~h}^{-1}$. Treatment options were discussed with the patient and given the existence of an epidural abscess and the severity of the lytic lesion at T11/T12 with an inability to ambulate, she was offered surgery.

Operation: After the patient was intubated uneventfully she underwent an extracavitary approach that has been described by other authors (Snell et al., 2006; Shen et al., 2008; Sciubba et al., 2007), T11-12 corpectomies, drainage of the epidural abscess, placement of expandable cage (Synex ${ }^{\circledR}$, Synthes, West Chester, PA) and T9-L3 posterior instrumentation and correction of the kyphotic deformity Fig. 4. Intraoperatively, purulent discharge was encountered in the affected vertebral bodies and samples were sent for culture. Intraoperative monitoring using Somatosensory Evoked Potentials (SSEPs) and Motor Evoked Potentials (MEPs) remained at baseline throughout the procedure. Two drains were placed; the muscles and fascia were closed in layers and the skin with staples. There were no intraoperative complications. Her postoperative examination revealed full strength in all her extremities.

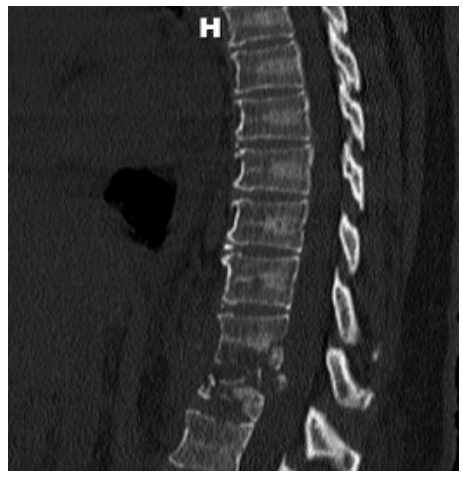

Fig. 1: Preoperative sagittal Computed Tomography (CT) image of the thoracic spine revealing a destructive lesion at T11 and T12 causing a kyphotic deformity with a retropulsed fragment into the spinal canal

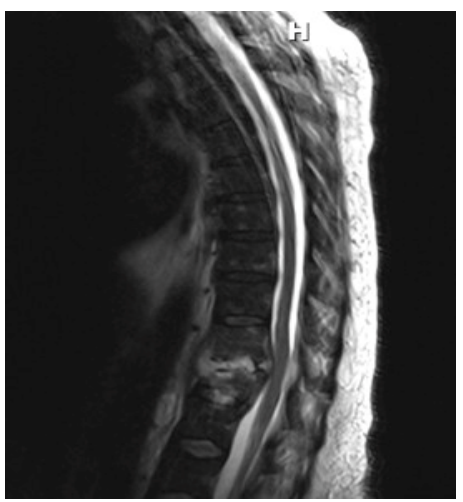

Fig. 2: Preoperative sagittal T2 weighted Magnetic Resonance Imaging (MRI) of the thoracic spine revealing a destructive lesion at $\mathrm{T} 11$ and $\mathrm{T} 12$ causing a kyphotic deformity and an epidural abscess causing spinal cord compression

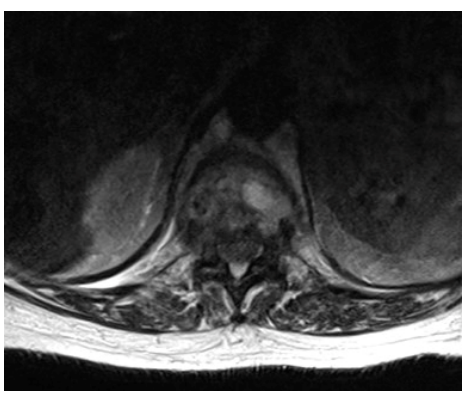

Fig. 3: Preoperative axial T2 weighted Magnetic Resonance Imaging (MRI) at the level of the T12 vertebra revealing a destructive lesion of the T12 vertebral body and an epidural abscess causing spinal cord compression 


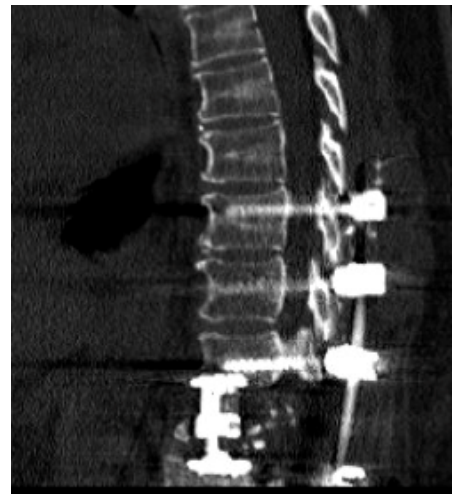

Fig. 4: Postoperative sagittal CT of the thoracic spine demonstrating the position of the construct

Post-operative course: Postoperatively, she was transferred to the neurosurgical Intensive Care Unit (ICU) overnight and was consequently transferred to the regular floor. The infectious disease service was consulted and she was kept on levofloxacin. Postoperatively, her motor strength remained normal in all her extremities and her sensory examinations remained intact to light touch and pinprick. Her pain was well controlled. On postoperative day 4, she was transferred to an acute rehabilitation center to follow a course of physical and occupational therapy in order to gain mobility and ambulatory independence. She also continued on levofloxacin orally ( $750 \mathrm{mg}$ daily) for an additional 6 weeks post-operatively. Further workup was performed in an effort to reveal any immunologic compromise, infection with HIV and sickle cell anemia or sickle cell trait, which was negative. On follow up visits, she was able to ambulate without any assistance and her back pain had resolved except from some stiffness. Likewise, her infection had resolved and laboratory values had normalized two months postoperatively (WBC was $6,160 \mathrm{~mm}^{-3}$, CRP was $0.5 \mathrm{mg} \mathrm{dL}^{-1}$ and ESR was $30 \mathrm{~mm} \mathrm{~h}^{-1}$ ).

\section{RESULTS AND DISCUSSION}

Salmonella is a non-spore-forming gram-negative bacillus of the family Enterobacteraciae, which can be easily cultured on simple media (Osebold, 2008). In most cases humans ingest the organism from contaminated food or water and their small bowel becomes its habitat (Osebold, 2008). Salmonella can be either quiescent in an asymptomatic carrier state or manifest as gastroenteritis, typhoid fever, or bacteremia (Cobos et al., 1993; Gupta et al., 2004). Infections with this bacterium represent a rare cause of osteomyelitis since the advent of antibiotics, accounting for approximately<\% of all cases (Cobos et al., 1993; Gupta et al., 2004). These cases are thought to occur secondary to hematogenous spread after an episode of bacteremia (Ozturk et al., 2006; Cobos et al., 1993; Gupta et al., 2004) as is the case with our patient. Most incidences of salmonella osteomyelitis are caused by $S$. typhimurium and S. enteritidis, whereas the typhi serotypes have been rarely reported (Cobos et al., 1993).

Salmonella osteomyelitis is usually seen in patients that are immunologically compromised (Osebold, 2008). It occurs more often in people suffering from sickle cell disease or sickle cell traitand other hemoglobinopathies, but also in conditions that may suppress the immune system such as chronic alcoholism, hematologic malignancies, Systemic Lupus Erythematosus (SLE), Diabetes Mellitus (DM), solid tumors, long term therapy with steroids and possibly Acquired Immunodeficiency Syndrome (AIDS) (Cobos et al., 1993; Gupta et al., 2004; Chambers et al., 2000; Vichinsky and Lubin, 1980; Wu et al., 2004). In osteomyelitis patients without sickle-cell anemia the infection is attributed to Salmonella in only $0.5 \%$ of the cases, one forth of which involves the spinal column (Ozturk et al., 2006). The most common spinal region involved in salmonellosis is the lumbar area, followed by the thoracic region that was the one affected in our patient (Santos and Sapico, 1998). The major clinical manifestations and laboratory findings include fever, back pain, leukocytosis and elevated ESR and CRP (Ozturk et al., 2006; Wu et al., 2004; Santos and Sapico, 1998; Carragee et al., 1997).

Various authors have reported the rare occurrence of salmonella osteomyelitis involving the spine in immunocompetent patients (Ozturk et al., 2006; Santos and Sapico, 1998; Carvell and MacLarnon, 1981; Dolan et al., 1987; Hunt et al., 1996; Hunt, 1965; Le, 1982; Miller et al., 1988; Mnaymneh, 1977; O'Keeffe et al., 1978; Ortiz-Neu et al., 1978; Sapico and Montgomerie, 1979; Schweitzer et al., 1971; Govender et al., 1999; Cottalorda et al., 1997; Abdullah et al., 2008; Acharya and Bhatnagar, 2004; Akagi et al., 1998). From these groups a few have reported surgical intervention (Ozturk et al., 2006; Wu et al., 2004; Hunt et al., 1996; Le, 1982; Mnaymneh, 1977; Abdullah et al., 2008; Acharya and Bhatnagar, 2004; Akagi et al., 1998) for the treatment of the infection (Table 1). None of these case reports though, provides a possible explanation for this incidence. Salmonella infection is more prone to disseminate in areas of inflammation or trauma (Osebold, 2008), probably because of the higher vascularity and the local inflammatory activity rendering the capillaries of the affected tissue more permeable. We speculate that the cause of our patient's osteomyelitis was her mild spinal trauma secondary to the fall she sustained. 
Am. J. Infect. Dis., 6 (2): 44-49, 2010

Table 1: Reports of immunocompetent patients treated with surgery for salmonella spondylodiscitis

\begin{tabular}{|c|c|c|c|c|}
\hline Author & Year & Procedure & Indication & Outcome \\
\hline \multirow[t]{2}{*}{ Mnaymneh } & 1977 & $\begin{array}{l}\text { Anterior drainage of paravertebral abscess and } \\
\text { vertebral interbody fusion with bone graft }\end{array}$ & $\begin{array}{l}\text { T8-9 spondylodiscitis, } \\
\text { spinal cord compression }\end{array}$ & $\begin{array}{l}\text { Mild lower extremity } \\
\text { weakness } 6 \text { months } \\
\text { postoperatively } \\
\text { consequently lost at follow up }\end{array}$ \\
\hline & & $\begin{array}{l}\text { Anterior drainage of paravertebral abscess and } \\
\text { vertebral interbody fusion with bone graft }\end{array}$ & $\begin{array}{l}\text { L2-3 spondylodiscitis, } \\
\text { spinal cord compression }\end{array}$ & Neurologically intact \\
\hline Le & 1982 & $\begin{array}{l}\text { Anterior debridement and vertebral interbody } \\
\text { fusion with bone graft }\end{array}$ & $\begin{array}{l}\text { L1-2 spondylodiscitis, back } \\
\text { pain refractory to antibiotic } \\
\text { treatment }\end{array}$ & Neurologically intact \\
\hline Hunt et al. & 1996 & Posterior debridement & Sacroiliac osteomyelitis & Neurologically intact \\
\hline Santos and Sapico & 1998 & $\begin{array}{l}\text { L4 hemilanectomy, L5 laminectomy, nerve root } \\
\text { decompression and debridement }\end{array}$ & $\begin{array}{l}\text { L5-S1 spondylodiscitis and } \\
\text { spondylolesthesis, epidural } \\
\text { abscess, cauda equina } \\
\text { syndrome }\end{array}$ & $\begin{array}{l}\text { Neurologically intact, mild } \\
\text { back pain }\end{array}$ \\
\hline Akagi et al. & 1998 & $\begin{array}{l}\text { Anterior debridement and vertebral interbody } \\
\text { fusion with bone graft }\end{array}$ & $\begin{array}{l}\text { C5-7 spondylodiscitis, } \\
\text { epidural abscess, spinal cord } \\
\text { compression, tetraplegia }\end{array}$ & $\begin{array}{l}\text { Ambulatory with crutches } 6 \\
\text { months postoperatively }\end{array}$ \\
\hline Acharya and Bhatnagar & 2004 & $\begin{array}{l}\text { Anterior debridement and anterior fixation } \\
\text { with bone graft }\end{array}$ & $\begin{array}{l}\text { L1-2 spondylodiscitis and } \\
\text { L1-2 paravertebral collection }\end{array}$ & $\begin{array}{l}\text { Ambulating on custom spinal } \\
\text { orthoses }\end{array}$ \\
\hline Ozturk et al. & 2006 & $\begin{array}{l}\text { Anterior debridement, T8-10 corpectomy with } \\
\text { titanium mesh cage, T6-12 posterior } \\
\text { instrumentation and fusion }\end{array}$ & $\begin{array}{l}\text { T9 spondylodiscitis, spinal } \\
\text { cord compression }\end{array}$ & Neurologic status at Frankel E \\
\hline Abdullah et al. & 2008 & $\begin{array}{l}\text { T3-4 costotransversectomy and epidural } \\
\text { abscess drainage }\end{array}$ & Epidural abscess & Not mentioned \\
\hline
\end{tabular}

Salmonella spodylodiscitis is usually treated with the appropriate antibiotic therapy. Cases of medically controlled Salmonella spodylodiscitis and paravertebral abscess have been reported (Arnold et al., 1997). Surgical intervention is necessary however, when epidural abscesses, neurologic impairment or instability are present (Arnold et al., 1997; Chang, 2005; Matsui et al., 1998; Suchomel et al., 2003). Other indications include intractable pain, failed medical therapy and the need to establish tissue diagnosis (Arnold et al., 1997; Chang, 2005; Matsui et al., 1998; Suchomel et al., 2003). There is much evidence suggesting that better outcomes can be achieved with surgery in comparison to medical treatment (Quinones-Hinojosa et al., 2004) in patients with intractable pain.

There has been a long lasting debate on whether instrumentation in spondylodiscitis patients increases their risk of persistent infection by providing a scaffold for biofilm formation and thus reducing antibiotic effectiveness (Korovessis et al., 2008). Titanium mesh cages though appear to be a safe choice since titanium has been shown to be less prone to bacterial colonization than stainless steel (Chang and Merritt, 1991). There is currently strong evidence in the literature that titanium mesh cages provide better biomechanical results than simple bone grafts in spondylodiscitis patients, without increasing the risk of complications and especially the risk of persistent infection (Ozturk et al., 2006; Korovessis et al., 2008; Kuklo et al., 2006; Liljenqvist et al., 2003; Fang et al., 1994; Altman et al., 1996; Bhat et al.,
1999). Hee et al. (2002) was the first group to support the superiority of titanium cages in the treatment of spondylodiscitis patients. They have shown a statistically significant improvement in sagittal alignment in patients receiving cages or posterior instrumentation only in comparison to those treated with simple bone grafts. Additionally, those who received cages had greater correction of their coronal alignment than did the patients without cage $(\mathrm{p}=0.0006)$.

Various groups have extended these promising results with titanium mesh cages to the use of the newer expandable cages in patients with the same characteristics (Auguste et al., 2006; Arts and Peul, 2008). However, this is the first report of the use of an expandable cage after corpectomy in Salmonella spondylodiscitis in an immunocompetent patient. To minimize the surgical burden of our patient we used for both procedures a single extracavitary approach that has been previously described (Snell et al., 2006; Shen et al., 2008; Sciubba et al., 2007) was the first group that showed excellent results with the use of the extracavitary approach in patients with metastatic tumors of the lumbar and thoracic spine. Sciubba et al. (2007) have expanded the use of this technique to include patients with spinal trauma and prior vertebral osteomyelitis. These patients however, were operated for correction of deformity several years after their infection has been medically treated with success. On the other hand, our patient is the first one reported who has been operated with this technique during the active phase of a salmonella infection, a factor that did not negatively affect her recovery. Despite the limited 
surgical exposure, our patient did not develop any intra or postoperative complications, she remained neurologically intact and her infection resolved promptly. It is felt (Sciubba et al., 2007) that this technique imparts a lower morbidity associated with a lone posterior approach, while conferring the benefits of anterior spine decompression and active intraoperative kyphosis correction via an expandable cage.

\section{CONCLUSION}

In summary, we report the first case of salmonella spondylodiscitis in an immunocompetent patient, treated with an expandable cage for corpectomy reconstruction and posterior instrumentation through an extracavitary approach. The surgical exposure allowed for removal of the infected bone, drainage of the epidural abscess and stabilization of the spine. We therefore demonstrate that this procedure is an excellent option for the treatment of patients with infectious processes of the spine that needs surgical drainage and deformity correction.

\section{REFERENCES}

Abdullah, S.H., O.A. Ata and N. El-Adwan, 2008. Thoracic spinal epidural abscess caused by Salmonella typhi. Neurol Med. Chir (Tokyo), 48: 140-142. PMID: 18362463

Acharya, S. and P. Bhatnagar, 2004. Salmonella spinal osteomyelitis: A case report and review of literature. Nerol. India, 52: 499-500. PMID: 15626845

Akagi, S., H. Shimada, I. Kato, T. Saito and R. Ogawa, 1998. Cervical spondylitis and epidural abscess caused by Salmonella enteritidis with tetraplegia. Orthopedics, 21: 1289-1291. PMID: 9867305

Altman, G.T., D.T. Altman and K.F. Frankovitch, 1996. Anterior and posterior fusion for children with tuberculosis of the spine. Clin. Orthop. Relat. Res., 325: 225-231. PMID: 8998880

Arnold, P.M., P.N. Baek, R.J. Bernardi, E.A. Luck and S.J. Larson, 1997. Surgical management of nontuberculous thoracic and lumbar vertebral osteomyelitis: Report of 33 cases. Surg. Neurol., 47: 551-561. PMID: 9167780

Arts, M.P. and W.C. Peul, 2008. Vertebral body replacement systems with expandable cages in the treatment of various spinal pathologies: A prospectively followed case series of 60 patients. Neurosurgery, 63: 537-544. PMID: 18812965

Auguste, K.I., C. Chin, F.L. Acosta and C.P. Ames, 2006. Expandable cylindrical cages in the cervical spine: A review of 22 cases. J. Neurosurg. Spine., 4: 285-291. DOI: 10.3171/spi.2006.4.4.285
Bhat, A.L., G.L. Lowery and A. Sei, 1999. The use of titanium surgical mesh-bone graft composite in the anterior thoracic or lumbar spine after complete or partial corpectomy. Eur. Spine J., 8: 304-309. DOI: 10.1007/s005860050178

Carragee, E.J., D. Kim, T. van der Vlugt and D. Vittum, 1997. The clinical use of erythrocyte sedimentation rate in pyogenic vertebral osteomyelitis. Spine, 22: 2089-2093. PMID: 9322319

Carvell, M.B. and J.C. MacLarnon, 1981. Chronic osteomyelitis of the thoracic spine due to Salmonella typhi: A case report. Spine, 6: 527-530. PMID: 7302688

Chambers, J.B., D.A. Forsythe, S.L. Bertrand, H.J. Iwinski and D.E. Steflik, 2000. Retrospective review of osteoarticular infections in a pediatric sickle cell age group. J. Pediatr. Orthop., 20: 682-685. PMID: 11008753

Chang, C.C. and K. Merritt, 1991. Effect of Staphylococcus epidermidis on adherence of Pseudomonas aeruginosa and Proteus Mirabilis to Polymethyl Methacrylate (PMMA) and gentamicin-containing PMMA. J. Orthop. Res., 9: 284-288. PMID: 1899449

Chang, I.C., 2005. Salmonella Spondylodiscitis in Patients without Sickle Cell Disease. Clin. Orthop. Relat., 430: 243-247. DOI: 10.1097/01.blo.0000137561.82099.d5

Cobos, J.A., J.H. Calhoun and J.T. Mader, 1993. Salmonella typhi osteomyelitis in a nonsickle cell patient: A case report. Clin. Orthop., 288: 277-281. DOI: 10.1097/00003086-199303000-00035

Cottalorda, J. F. Varlet, D. Allard and N. Dutour, 1997. Salmonella spondylitis. J. Pediatr. Orthop. B., 6: 73-75. PMID: 9039673

Dolan, S.A., E.D. Everett and M.C. Harper, 1987. Salmonella vertebral osteomyelitis treated with cefotaxime. Arch Int. Med., 147: 1667-1668. DOI: 10.1001/archinte.147.9.1667

Fang, D., K.M. Cheung, I.D. Dos Remedios, Y.K. Lee and J.C. Leong, 1994. Pyogenic vertebral osteomyelitis: treatment by anterior spinal debridement and fusion. J. Spinal Disord., 7:173-180.

DOI: 10.1097/01.BRS.0000109410.46538.74

Govender, S., A.H. Parbhoo, M.N. Rasool and J. Maharaj, 1999. Salmonella typhi spondylitis. J. Pediatr. Orthop., 19: 710-714. PMID: 10573337

Gupta, S.K., A. Pandit, D.G. White and P.D. Evans, 2004. Salmonella osteomyelitis of the thoracic spine: An unusual presentation. Postgrad. Med. J., 80: 110-111. DOI: $10.1136 / \mathrm{pmj} .2002 .002592$ 
Hee, H.T., M.E. Majd, R.T. Holt and D. Pienkowski, 2002. Better treatment of vertebral osteomyelitis using posterior stabilization and titanium mesh cages. J. Spinal Disord. Tech., 15: 149-156. PMID: 11927825

Hunt, B.K., W.K. Gibson and D.K. Mitchell, 1996. Salmonella braenderup sacroiliac osteomyelitis in a nonsickle cell patient. Bull. Hosp. Joint Dis., 55: 86-87. PMID: 8879744

Hunt, D.D., 1965. Cervical spondylitis caused by Salmonella oranienburg: A case report. J. Bone Joint Surg. Am., 47: 1243-1637. PMID: 14337785

Korovessis, P., T. Repantis, P. Iliopoulos and A. Hadjipavlou, 2008. Beneficial influence of titanium mesh cage on infection healing and spinal reconstruction in hematogenous septic spondylitis: A retrospective analysis of surgical outcome of twenty-five consecutive cases and review of literature. Spine, 33: 759-767. DOI: 10.1097/BRS.0b013e318187875e

Kuklo, T.R., B.K. Potter, R.S. Bell, R.R. Moquin and M.K. Rosner, 2006. Single-stage treatment of pyogenic spinal infection with titanium mesh cages. J. Spinal Disord. Tech., 19: 376-382. DOI: 10.1097/01.bsd.0000203945.03922.f6

Le, C.T., 1982. Salmonella vertebral osteomyelitis: A case report with literature review. Am. J. Dis Child, 136: 722-724. PMID: 6213144

Liljenqvist, U., T. Lerner, V. Bullmann, L. Hackenberg and H. Halm et al., 2003. Titanium cages in the surgical treatment of severe vertebral osteomyelitis. Eur. Spine J., 12: 606-612. DOI: 10.1007/s00586-003-0614-Z

Matsui, H., N. Hirano and Y. Sakaguchi, 1998. Vertebral osteomyelitis: An analysis of 38 surgically treated cases. Eur. Spine J., 7: 50-54. DOI: $10.1007 / \mathrm{s} 005860050027$

Miller, M.E., G.R. Fogel and W.K. Dunham, 1988. Salmonella spondylitis: A review and report of two immunologically normal patients. J. Bone Joint Surg. Am., 70: 463-466. PMID: 3346277

Mnaymneh, W., 1977. Salmonella spondylitis: Report of two cases. Clin. Orthop. Relat. Res., 126: 235-238.

O'Keeffe, M., D. Gleeson, G. Lee and M.J. Whelton, 1978. Brief report: Salmonella agona osteomyelitis of spine. Israeli J. Med. Sci., 147: 36-37.

Ortiz-Neu, C., J.S. Marr, C.E. Cherubin and H.C. Neu, 1978. Bone and joint infections due to salmonella. J. Infect. Dis., 138: 820-828. PMID: 368264

Osebold, W.R., 2008. Systemic leptospirosis followed by salmonella vertebral osteomyelitis without sickling or immunosuppression. Spine, 33: 55-61. DOI: 10.1097/BRS.0b013e3181604708
Ozturk, C., M. Tezer, C. Mirzanli, F.E. Bilen and M. Aydogan et al., 2006. An uncommon cause of paraplegia: Salmonella spondylodiskitis. J. Spinal Cord Med., 29: 234-236. PMID: 16859227

Quinones-Hinojosa, A., P. Jun, R. Jacobs, W.S. Rosenberg and P.R. Weinstein, 2004. General principles in the medical and surgical management of spinal infections: A multidisciplinary approach. Neurosurg. Focus, 17: $1 . \quad$ DOI: 10.3171/foc.2004.17.6.1

Santos, E.M. and F.L. Sapico, 1998. Vertebral osteomyelitis due to salmonellae: Report of two cases and review. Clin. Infect. Dis., 27: 287-295. DOI: $10.1086 / 514668$

Sapico, F.L. and J.Z. Montgomerie, 1979. Pyogenic vertebral osteomyelitis: Report of nine cases and review of the literature. Rev. Infect. Dis., 1: 754-763. PMID: 542761

Schweitzer, G., G.M. Hoosen and J.M. Dunbar, 1971. Salmonella typhi spondylitis: An unusual presentation. South African Med. J., 30: 126-128. PMID: 4251061

Sciubba, D.M., G.L. Gallia and M.J. McGirt, G.F. Woodworth and I.M. Garonzik et al., 2007. Thoracic kyphotic deformity reduction with a distractible titanium cage via an entirely posterior approach. Neurosurgery, $\quad 60$ : 223-230. DOI: 10.1227/01.NEU.0000255385.18335.A8

Shen, F.H., I. Marks, C. Shaffrey, J. Ouellet and V. Arlet, 2008. The use of an expandable cage for corpectomy reconstruction of vertebral body tumors through a posterior extracavitary approach: A multicenter consecutive case series of prospectively followed patients. Spine J., 8: 329-339. DOI: 10.1016/j.spinee.2007.05.002

Snell, B.E., F.F. Nasr and C.E. Wolfla, 2006. Singlestage thoracolumbar vertebrectomy with circumferential reconstruction and arthrodesis: Surgical technique and results in 15 patients. Neurosurgery, 58: 263-269. DOI: 10.1227/01.NEU.0000209034.86039.39

Suchomel, P., P. Buchvald, P. Barsa, R. Lukas and T. Soukup, 2003. Pyogenic osteomyelitis of the odontoid process: Single stage decompression and fusion. Spine, 28: 239-244. PMID: 12811288

Vichinsky, E.P. and B.H. Lubin, 1980. Sickle cell anemia and related hemoglobinopathies. Pediatr. Clin. North Am., 27: 429-447. PMID: 6155657

Wu, K.C., T.C. Yao, K.W. Yeh and J.L. Huang, 2004. Osteomyelitis in patients with systemic lupus erythematosus. J. Reumatol., 31: 1340-1343. PMID: 15229953 